\title{
Influence of substrate temperature and bias voltage on the optical transmittance of TiN films
}

\author{
H. Zafer Durusoy ${ }^{\mathrm{a}, *}$, Özlem Duyar ${ }^{\mathrm{a}}$, Atilla Aydınlı ${ }^{\mathrm{b}}$, Feridun Ay \\ ${ }^{a}$ Department of Physics Engineering, Hacettepe University, Beytepe, 06532 Ankara, Turkey \\ ${ }^{\mathrm{b}}$ Physics Department, Bilkent University, Bilkent 06539 Ankara, Turkey
}

Received 25 June 2002; received in revised form 29 October 2002; accepted 6 November 2002

\begin{abstract}
Titanium nitride (TiN) thin films were prepared by means of reactive DC sputtering on quartz and sapphire substrates. Structural, electrical and optical effects of deposition parameters such as thickness, substrate temperature, substrate bias voltage were studied. The effect of substrate temperature variations in the $100-300^{\circ} \mathrm{C}$ range and substrate bias voltage variations in the $0-200 \mathrm{~V}$ DC range for $45-180 \mathrm{~nm}$ thick TiN films were investigated. Temperaturedependent electrical resistivity in the $100-350 \mathrm{~K}$ range and optical transmission in the $300-1500 \mathrm{~nm}$ range were measured for the samples. In addition, structural and morphological properties were studied by means of XRD and STM techniques.

The smoothest surface and the lowest electrical resistivity was recorded for the optimal samples that were biased at about $V_{\mathrm{s}}=-120 \mathrm{~V}$ DC. Unbiased films exhibited a narrow optical transmission window between 300 and $600 \mathrm{~nm}$. However, the transmission became much greater with increasing bias voltage for the same substrate temperature. Furthermore, it was found that lower substrate temperatures produced optically more transparent films.

Application of single layers of $\mathrm{MgF}_{2}$ antireflecting coating on optimally prepared TiN films helped increase the optical transmission in the visible region to more than $40 \%$ for $45 \mathrm{~nm}$ thick samples.
\end{abstract}

(C) 2003 Elsevier Science Ltd. All rights reserved.

Keywords: Titanium nitride; Optical transmittance; Electrical resistance; AR coating

\section{Introduction}

For many years, TiN films have been studied in order to utilise its noble properties such as high mechanical hardness, high corrosion resistance, low frictional constant and broad thermodynamic stability. In addition, mechanical properties of TiN has marked it as one of the primary materials for hard coatings and its bright golden colour has

\footnotetext{
*Corresponding author.

E-mail address: zaferd@pamukkale.edu.tr (H.Z. Durusoy).
}

added more value to this unique material. TiN has also found use in micro-electronics applications such as diffusion barriers, electrodes and Shottky contacts due to its high electrical conductivity and chemical stability [1-7]. Recently, TiN thin films have been studied for further applications as optical coatings, antireflecting coatings (ARC) and antistatic coatings. [8] Liquid crystal displays, CRT displays and special filter lenses are some of the areas of potential applications [8-11].

There are many ways to prepare TiN films [1-12]. One of the common techniques is reactive 
sputtering with substrate bias. In this approach, substrates are biased to a negative potential while $\mathrm{Ti}$ is sputtered in the presence of Nitrogen gas flow. Previously, it was shown that TiN films can only be grown in a certain range of $\mathrm{N}_{2}$ flow rates and that golden coloured, smooth and low resistivity TiN films could be grown by this method [3-8,12-14,16-18]. For substrate temperature $T_{\mathrm{S}}=300^{\circ} \mathrm{C}$ and $\left|V_{\mathrm{S}}\right| \sim 80-160 \mathrm{~V}$ DC it was found that smaller grain nucleation started and voids in the grain boundaries decreased [1]. For nitrogen flow rate $\phi_{N_{2}}=2.1 \mathrm{sccm}$ and $\left|V_{\mathrm{S}}\right|=120 \mathrm{~V}$ DC fully stoichiometric TiN films were prepared. It is assumed that increased energy of the impinging ions and atoms promotes surface diffusion to fill voids. Furthermore, with higher bias voltage, nucleation was enhanced and resulted in smaller grain size and higher packing density [11]. Growth of (111) preferential orientation corresponds to high electrical resistivity, whereas growth of (200) peak corresponds to lower electrical resistivity [14]. Usually, the (1 111 ) peak is observed in films that are thicker than $1 \mu \mathrm{m}$ [15].

In recent studies, transparency of TiN films in the visible region have been studied [8-11]. $\mathrm{TiN}_{X}$ films of $50 \mathrm{~nm}$ thickness that were prepared by reactive sputtering method exhibited an optical transparency of $3.8 \%$ centred at wavelength $\lambda=444 \mathrm{~nm}$ [16]. In films that were made by ion assisted cathodic arc method and with $700 \mathrm{eV} \mathrm{N} \mathrm{N}_{2}$ ion beam bombardment, $\mathrm{N} / \mathrm{Ti}=1.3$ ratio yielded $33.5 \%$ transparency centred at $620 \mathrm{~nm}$ while

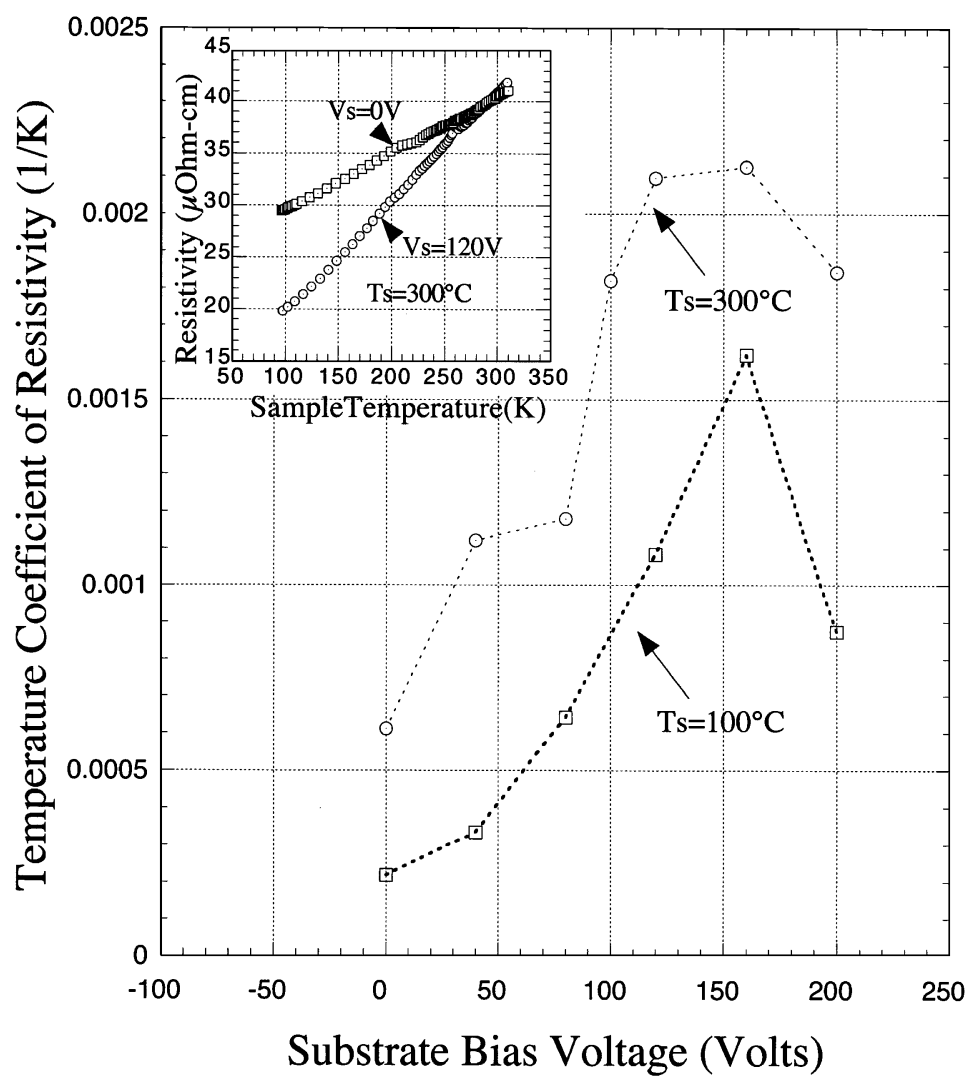

Fig. 1. Substrate bias voltage $\left(V_{\mathrm{s}}\right)$ dependence of temperature coefficient of resistivity (TCR) for $100^{\circ} \mathrm{C}$ and $300^{\circ} \mathrm{C}$ substrate temperatures. For about $-150 \mathrm{~V}$ DC bias value the highest TCR is obtained for both temperatures. Inset shows variation of resistivity with sample temperature for biased an unbiased thin films of thickness $t=180 \mathrm{~nm}$. Biased films have a much lower porosity and resistivity which results in a higher TCR. 
$\mathrm{N} / \mathrm{Ti}=1.0$ ratio yielded only $7.5 \%$ centred at $411 \mathrm{~nm}$ [9]. It is determined that bombardment resulted in mostly $\mathrm{Ti}$ vacancies in the film structure. Furthermore, a marked increase in the infrared transparency for increasingly non-stoichiometric N/Ti-ratio samples were detected. For stoichiometric samples, the transparency is only limited to the visible region with UV and IR regions blocked. Using $(n)$ and $(k)$ values obtained through spectroscopic-ellipsometric measurements, Kim et al. [8] obtained wide band ARC on glass substrates with $\mathrm{TiN}_{X}$ films coated by a single layer of $\mathrm{SiO}_{2}$. For $\mathrm{TiN}_{X}-\mathrm{SiO}_{2}$ two layer films on glass, reflection in the visible was measured to be less than $0.5 \%$ while peak transparency was

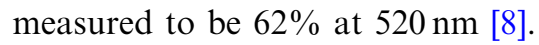

\section{Experimental}

In this study, a reactive DC sputtering system has been used with a base pressure $5 \times 10^{-7}$ Torr to deposit $\mathrm{TiN}_{X}$ films on quartz and sapphire substrates. After determining optimal gas flow, pressure and power values, all experiments were carried out under the same conditions. $\mathrm{Ar}$ and $\mathrm{O}_{2}$ gases were $99.999 \%$ pure and introduced via needle valves to adjust gas pressures such that the nitrogen partial pressure was $15 \%$ in the chamber. Total gas pressure was kept constant at about 4 mTorr and a magnetron power of $60 \mathrm{~W}$ was applied to the sputtering gun at a substrate-source distance of $5 \mathrm{~cm}$ in an onaxis deposition geometry. A $99.99 \%$ pure titanium disc was used as the sputtering target. When needed, temperature of the substrate was varied between $100^{\circ} \mathrm{C}$ and $300^{\circ} \mathrm{C}$ and constantly monitored by two K-type thermocouples. Both substrates and $\mathrm{Ti}$ sputter source were plasmacleaned prior to actual deposition of the film and this step was determined to have an important effect on the final film quality. A series of experiments were conducted for two substrate temperatures $\left(T_{\mathrm{s}}=100\right.$ and $\left.300^{\circ} \mathrm{C}\right)$ at
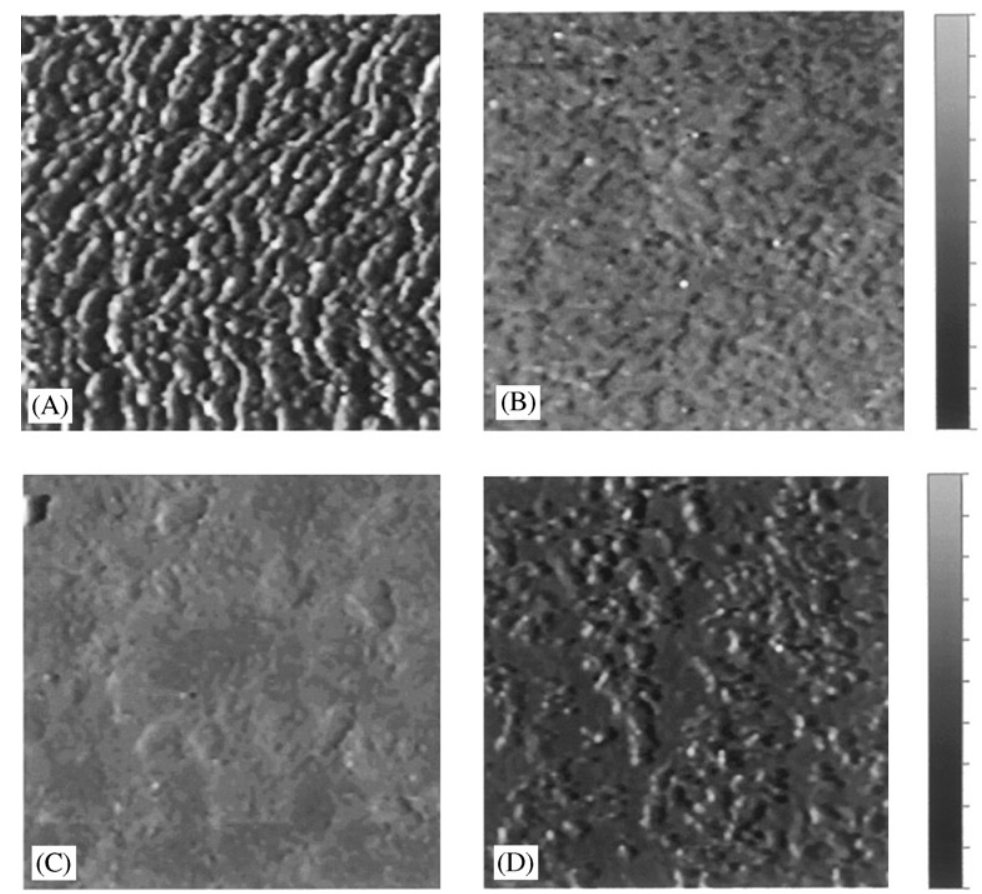

Fig. 2. STM micrographs showing surface morphology of biased and unbiased samples of $t=90 \mathrm{~nm}$ for different substrate temperatures. Each side of the micrographs is $250 \mathrm{~nm}$ long. The side bar represents a full-scale, vertical variation of $30 \mathrm{~nm}$. (A) $T_{\mathrm{s}}=100^{\circ} \mathrm{C}, V_{\mathrm{s}}=0 \mathrm{~V} \mathrm{DC},(\mathrm{B}) T_{\mathrm{s}}=300^{\circ} \mathrm{C}, V_{\mathrm{s}}=0 \mathrm{~V} \mathrm{DC},(\mathrm{C}) T_{\mathrm{s}}=300^{\circ} \mathrm{C}, V_{\mathrm{s}}=120 \mathrm{~V} \mathrm{DC},(\mathrm{D}) T_{\mathrm{s}}=300^{\circ} \mathrm{C}, V_{\mathrm{s}}=200 \mathrm{~V} \mathrm{DC}$. 
three different thickness $(t=45, \quad 90, \quad$ and $180 \mathrm{~nm})$ while varying the bias voltage $\left(\left|V_{S}\right| \sim 0\right.$ $200 \mathrm{~V}$ DC). Typical duration of the deposition was about $30 \mathrm{~min}$ for a $90 \mathrm{~nm}$ thick film with an approximate deposition rate of $0.05 \mathrm{~nm} /$ s. However, film thickness was observed to depend on bias voltage due to back-sputtering and increased packing density. In addition to visual examination, all samples were characterised by surface profilometer for thickness determination (Sloan Dektak), X-ray diffraction for structure analysis (Phillips 1140/00), scanning tunnelling microscope for surface morphology (custom built), low-temperature DC resistivity for electrical conductivity and a spectrophotometer (Varian Carry 5E) for optical transmittance.

\section{Results and discussion}

Electrical resistivity of the samples was measured through the four-point technique between 90 and $300 \mathrm{~K}$ in vacuum (Fig. 1). Room temperature resistivity was about $40 \mu \Omega \mathrm{cm}$ for samples of thickness $t=180 \mathrm{~nm}$. (Fig. 1, inset). The temperature coefficient of resistivity is defined as $\alpha=$ $\left(1 / R_{0}\right)(\mathrm{d} R(T) / \mathrm{d} T)$, where $R(T)$ is temperaturedependent resistance, $R_{0}$ is the residual resistance and $\alpha$ is the temperature coefficient of resistance which was calculated from the resistivity measurements. Samples prepared at $T_{\mathrm{s}}=100^{\circ} \mathrm{C}$ and $300^{\circ} \mathrm{C}$ for substrate bias voltage steps of $40 \mathrm{~V}$ DC between 0 and $200 \mathrm{~V}$ DC were investigated. As a result of increased cleanliness, higher packing density and preferential nucleation, biased samples

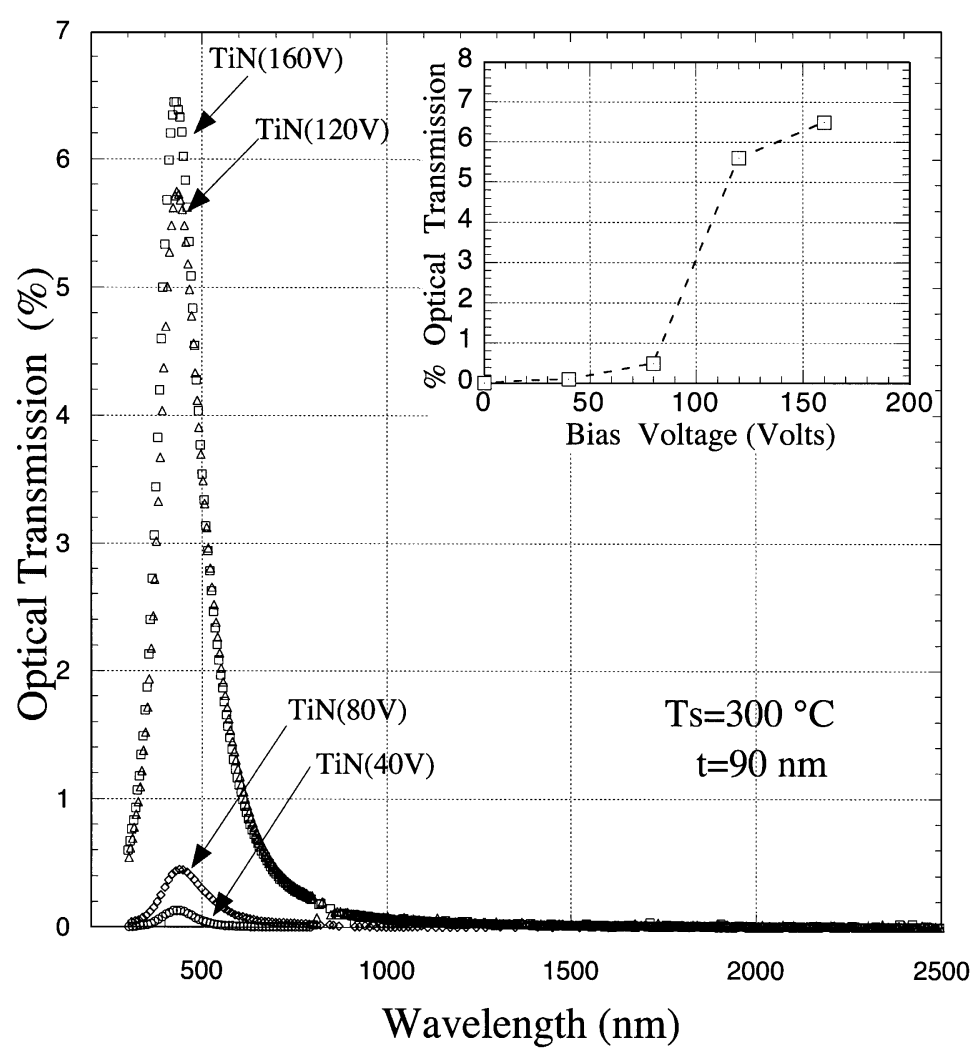

Fig. 3. For $t=90 \mathrm{~nm}$ films prepared at $T_{\mathrm{s}}=300^{\circ} \mathrm{C}$ an increased transmission is observed for increased biased voltage. Note that a redshifted transmission accompanies the increase in transmission peaks. Increase in transmittance with applied bias voltage is given in the inset. 
yielded a much lower resistivity up to an optimum bias value compared to those that were not biased (Fig. 1). Furthermore, XRD graphs indicated that for the optimal value of the bias voltage only (2 20$)$ plane peak was visible while both (220) and (200) plane peaks were observed for the unbiased samples.

A very smooth surface with no porous artefacts was observed for samples prepared under the optimal bias voltage. For values that were greater than the optimal value of the bias voltage, STM micrographs increasingly showed re-nucleation on existing grains and a much rougher surface (Fig. 2). It is also found that the bombardment damage, re-nucleation and preferential etching due to the biasing caused an increase in the resistivity of the films beyond the optimal bias value. As expected, substrate temperature was also observed to be an important parameter that contributed to surface smoothness and packing density when other variables were unchanged.

It has been a topic of search to find a material that blocks UV and IR spectra while transmitting in the visible spectrum. Interestingly, stoichiometric TiN films exhibit a small optical window in the visible region to meet this expectation. Transmission is limited to the $300-600 \mathrm{~nm}$ region and is strongly thickness dependent. Experiments showed that the width and amplitude of this transmission window is dependent on both substrate temperature and bias voltage (Figs. 3 and 4). Transmission decreased with increasing substrate

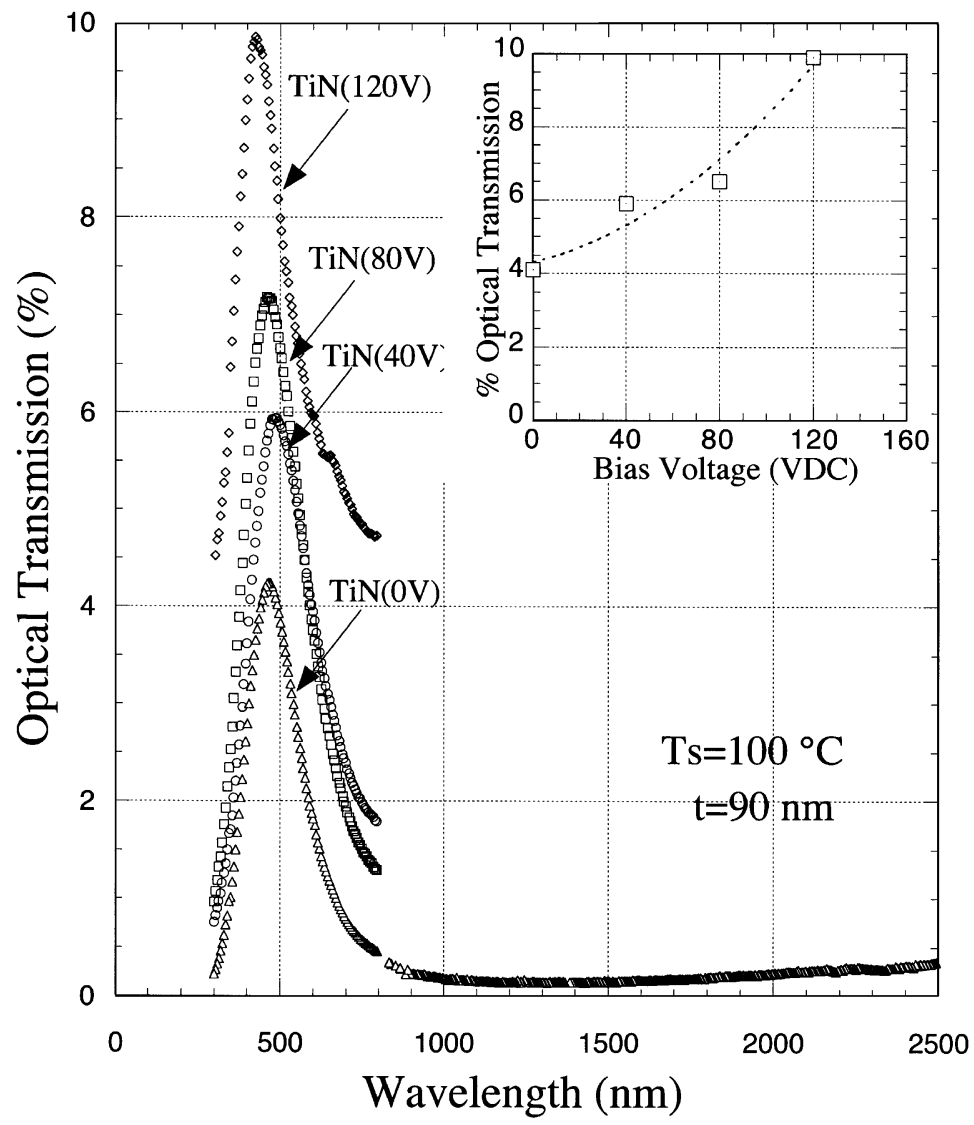

Fig. 4. For $t=90 \mathrm{~nm}$ films prepared at $T_{\mathrm{s}}=100^{\circ} \mathrm{C}$, an increased transmission is observed for increased biased voltage. Note that an asymmetry as well as a red-shifted transmission accompanies the increase in transmission peaks. Increase in transmittance with applied bias voltage is given in the inset. 
temperature but increased with applied bias voltage for all samples. The increase in peak values of transmittance with applied bias voltage is given in Figs. 3 and 4 insets. Clearly, at lower $T_{\mathrm{s}}$ values, transmittance is larger and increases more rapidly with bias voltage. Furthermore, it is also seen that while $T_{\mathrm{s}}=300^{\circ} \mathrm{C}$ films yielded a small and symmetrical transmission, $T_{\mathrm{s}}=100^{\circ} \mathrm{C}$ samples yielded a considerably larger and slightly redshifted transmission. It can be presumed that $\mathrm{Ti}$ vacancies and $\mathrm{N}$ intersititials that were created by bombardment were partially annealed out at higher substrate temperatures. Most of the optical features of $\mathrm{TiN}$ arise from the free carriers in Titanium $d$ band. Therefore, an increase in the number of Ti vacancies results in a decrease in the density of free carriers and shifts the screened plasma frequency to lower frequencies thereby creating the red-shifted spectra.

In order to explore the enhancement of optical transmission, single-layer $\mathrm{MgF}_{2}$ antireflecting coatings were first deposited on $90 \mathrm{~nm}$ films that were prepared under optimal conditions (Fig. 5). Quarter wave optical thickness $\mathrm{MgF}_{2}$ films were deposited using $n_{1}=n_{2} n_{0}$. In this calculation, $\sqrt{n_{0}}($ quartz $)=1.5, n_{1}(T i N) \approx 1.7$ [8] and $n_{2}\left(\mathrm{MgF}_{2}\right)=1.4$ were used and the central wavelength was taken as $\lambda=480 \mathrm{~nm}$. Thickness of $\mathrm{MgF}_{2}$ layers were pre-determined through the $t_{2}=$ $\lambda / 4 n_{2}$ expression. The results were better for $t=45 \mathrm{~nm}$ samples (Fig. 6) such that the transmission increased from $27 \%$ to $42 \%$ for $45 \mathrm{~nm}$ thick optimal films after $\mathrm{MgF}_{2}$ coating. An (effective) absorption coefficient was also obtained from the

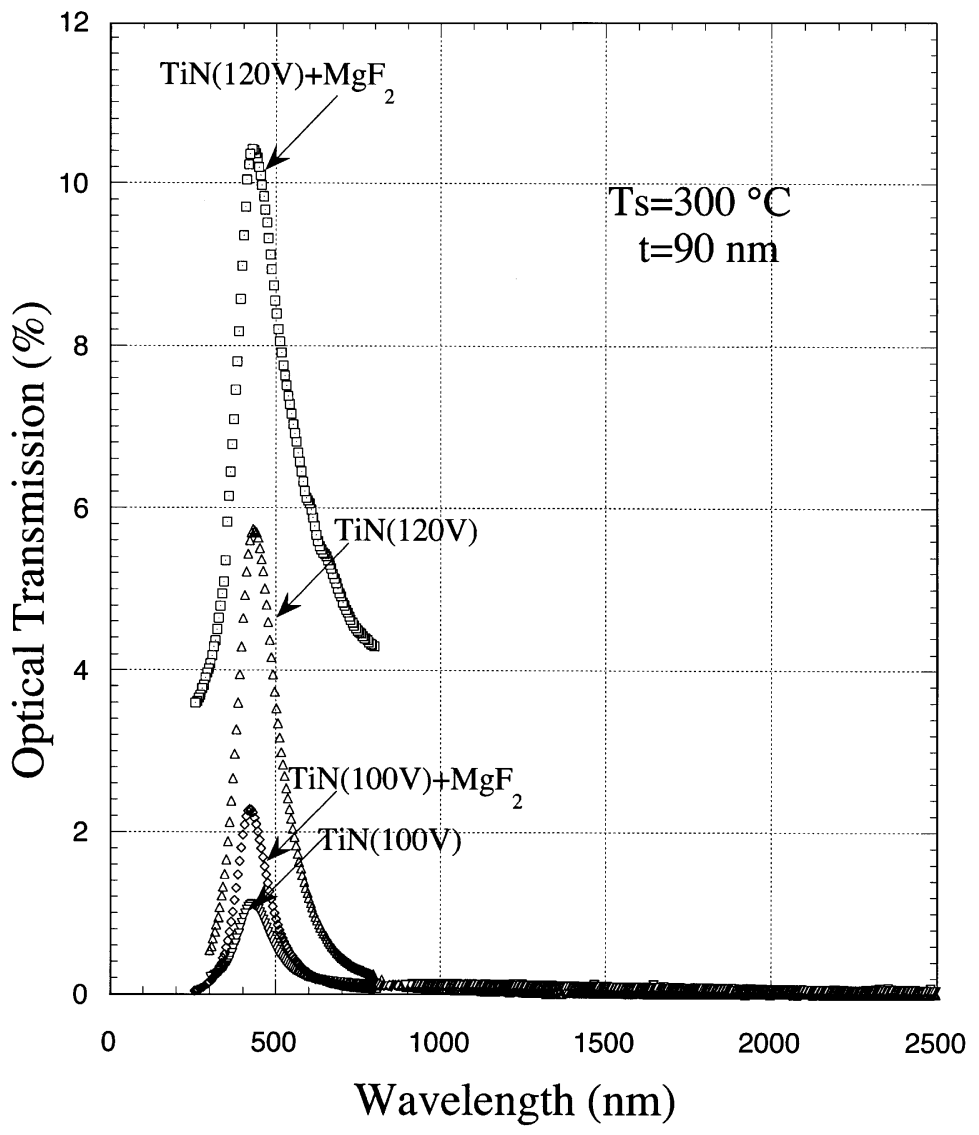

Fig. 5. Single-layer $\mathrm{MgF}_{2}$ antireflection coated $90 \mathrm{~nm}$ thick TiN films that yielded considerably higher transmission values compared to bare films. 


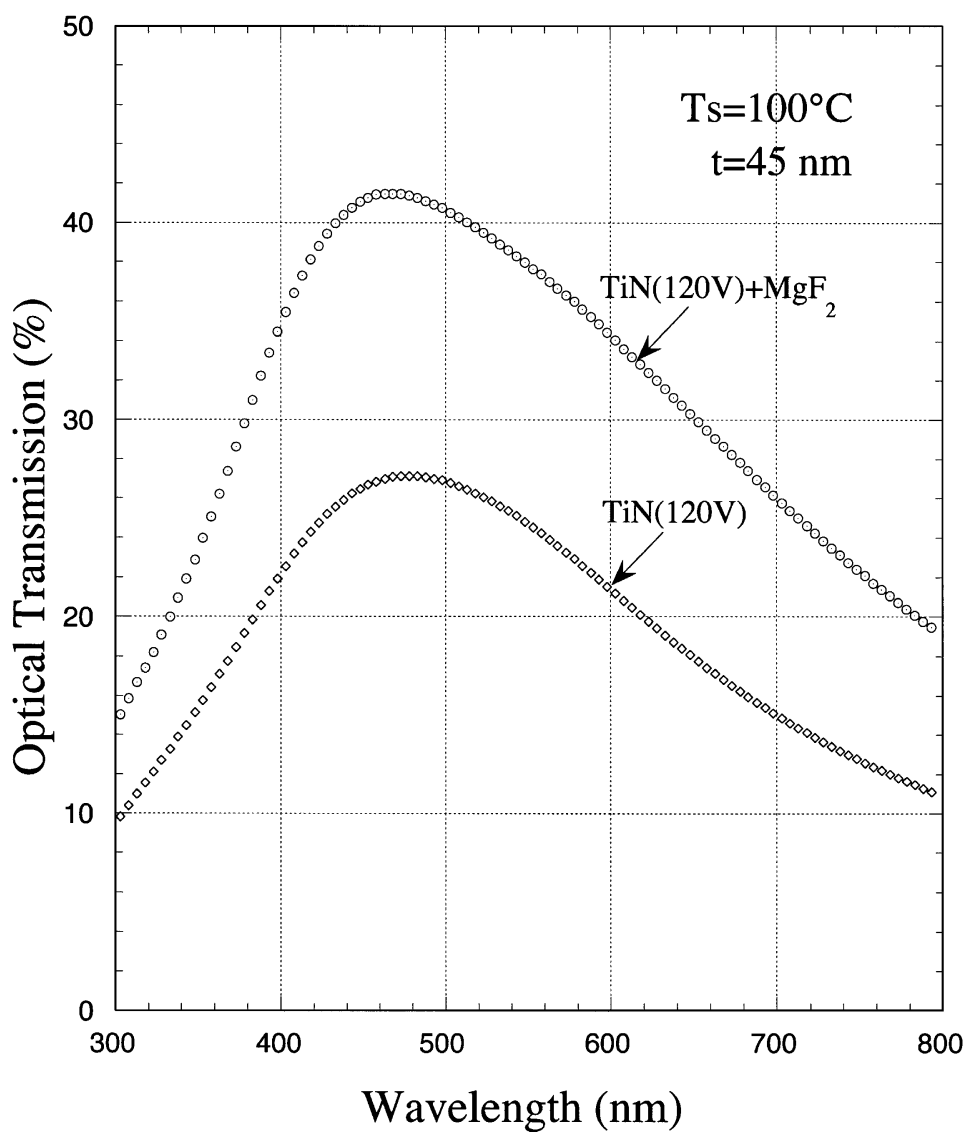

Fig. 6. The $45 \mathrm{~nm}$ thick single-layer $\mathrm{MgF}_{2}$ antireflection coated $\mathrm{TiN}$ films yielded a much higher transmission value compared to bare films.

data presented in Figs. 3 and 6 for bare TiN films as $\alpha=2.2 \times 10^{7} \mathrm{~m}^{-1}$ by the equation $I / I_{0}=e^{-\alpha t}$. An extrapolation attempt using this coefficient for possible $10 \mathrm{~nm}$ thick similar samples of this study suggests an approximate optical transmittance of $80 \%$ Indeed, an $82 \%$ peak optical transmittance was obtained for a bare TiN sample of $9 \mathrm{~nm}$ thickness (Fig. 7). Peak transmittance values for bare 90,45 and $9 \mathrm{~nm}$ thick films are plotted for comparison in Fig. 7 inset.

\section{Conclusion}

Bare samples prepared by ion assisted arcdeposition in Ref. [9] were reported to yield 34\% transmission with $700 \mathrm{eV} \mathrm{N}^{+}$ion bombardment.
Although thickness or electrical resistivity of these samples is not given, it can be anticipated that bombardment with such high-energy ions would severely degrade electrical and mechanical properties of the films. In another study, a $65 \%$ transmission in the visible range was obtained with $15 \mathrm{~nm}$ thick TiN films that were coated by a single $\mathrm{SiO}_{2}$ layer [8]. Compared to these studies, performance of both bare and $\mathrm{MgF}_{2}$ coated TiN films of this work seem very promising. Furthermore, $\mathrm{MgF}_{2}$ has much less absorption in this range and is easier to coat.

Optical transmittance can be increased without inducing structural, mechanical or electrical degradation of the optimal properties of the TiN films. Indeed, it has been shown in this study that it may be possible to have a large optical 


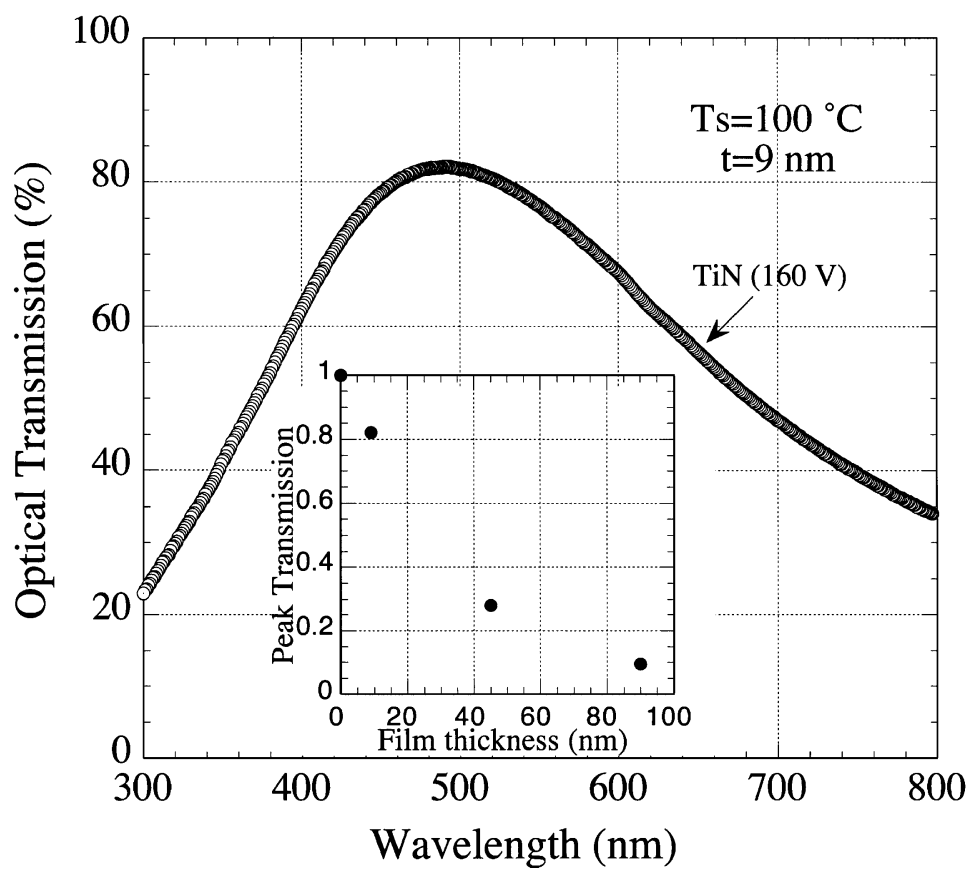

Fig. 7. Curve at the top belongs to the $90 \AA$ thick, bare TiN film that was prepared under the optimal conditions. Inset shows peak transmission values against thickness for various data points; $t=0,9,45$, and $90 \mathrm{~nm}$.

transmission in the VIS, while maintaining the optimised film properties by choosing appropriate film preparation parameters.

\section{Acknowledgements}

We are thankful to Dr. Cengiz Kocum for performing STM measurements. This study was partially supported by State Planning Agency through DPT-97K121320.

\section{References}

[1] Petrov I, Hultman L, Helmerson U, Sundgren JE. Thin Solid Films 1989;169:299-314.

[2] Erdemir A, Cheng CC. J Vac Sci Technol A 1991;9(3): 439-43.

[3] Logothetidis S, Meletis EI, Stergioudis G, Adjaottor AA. Thin Solid Films 1999;338:304-13.

[4] Tarniowy A, Mania R, Rekas M. Thin Solid Films 1997;311:93-100.
[5] Patsalas P, Charitidis C, Logothetidis S. Surf Coat Technol 2000;125:335-40.

[6] Valvoda V. JAlloys Compd 1995;219:83-7.

[7] Pécz B, Frangis N, Logothetidis S, Alexandrou I, Barna PB, Stoemenos J. Thin Solid Films 1995;268:57-63.

[8] Kim NY, Son YB, Oh JH, Hwangbo CK, Park MC. Surf Coat Technol 2000;128-129:156-60.

[9] Smith GB, Swift PD, Bendavid A. Appl Phys Lett 1999;75:630-3.

[10] Schmid PE, Sunaga MS, Levy F. J Vac Sci Technol A 1998;16(5):2870-5.

[11] Leng JM, Chen J, Fanton J, Senko M, Ritz K, Opsal J. Thin Solid Films 1998;313-314:308-13.

[12] Igasaki Y, Mitsuhashi H. Thin Solid Films 1980;70:17-25.

[13] Adjaottor AA, Meletis EI, Logothetidis S, Alexandrou I, Kokkou S. Surf Coat Technol 1995;76-77:142-8.

[14] Li-Jian Meng, dos Santos MP. Surf Coat Technol 1997; 90:64-70.

[15] Wen-Jun Chou, Ge-Ping Yu, Jia-Hong Huang. Surf Coat Technol 2001;140:206-14.

[16] Roquiny Ph, Bodart F, Terwagne G. Surf Coat Technol 1999;116-119:278-83.

[17] Combadiere L, Machet J. Surf Coat Technol 1996;88: 17-27.

[18] Duyar O. Effects of ion bombardment on the structural and electrical propertied of metallic thin films. MS Thesis, Hacetttepe University, Ankara, 2001. 